\title{
PEDAGOGIAS DE SER: ESCUTA E VISIBILIDADE DE CORPOS EM ANTOLOGIAS TRANS
}

\author{
Maximiliano Torres $^{1}$ (UERJ-FFP)
}

Resumo: A construção teórica, a percepção política e a necessidade da prática, fornecidas pelos estudos feministas e queer, possibilitam ampla visão sobre o próprio conceito de teoria que permite um alargamento do olhar no atravessamento pelos caminhos da crítica literária. Nesse sentido, ler literatura, se desarticula do espaço de pensar o texto, a partir das questões de valor, de significado, de tradição, de autoria ou de pontos de vista e da linguagem. Avançar com esse método é descontruir os alicerces de uma crítica normativa, que sustenta as bases ideológicas das desigualdades, uma vez que a leitura queer possibilita perceber a materialidade histórica do discurso e das subjetividades no campo literário. Assim, esse trabalho busca apresentar poemas da Antologia Trans - 30 poetas trans, travestis e não-binários (2017), como a inscrição de corpos que ressignificam os conceitos de valor e tomam visibilidade no campo da literatura.

Palavras-chave: Transexualidades. Poesia. Revisionismo. Crítica

\section{PEDAGOGIES OF BEING: LISTENING AND VISIBILITY OF BODIES IN ANTOLOGIA TRANS}

\begin{abstract}
Theoretical construction, political perception and the need for practice, provided by feminist and queer studies, allow for a broad view of the very concept of theory that allows a broadening of the gaze in crossing the paths of literary criticism. In this sense, reading literature, separates itself from the space of thinking about the text, based on questions of value, meaning, tradition, authorship or points of view and language. Advancing with this method is to deconstruct the foundations of a normative critique, which supports the ideological bases of inequalities, since queer reading makes it possible to realize the historical materiality of discourse and subjectivities in the literary field. Thus, this paper seeks to present poems from Antologia Trans - 30 poetas trans, travestis e não-binários (2017), as the inscription of bodies that resignify the concepts of value and gain visibility in the field of literature.
\end{abstract}

Keywords: Transsexualities. Poetry. Revisionism. Criticism.

${ }^{1}$ Universidade do Estado da Rio de Janeiro. E-mail: maxitorres@uol.com.br. 
Para João Innecco, pelo amor que nos une, pelo contágio energizante da sua juventude... pelo aprendizado de...

\author{
Vida sem título \\ O mundo é puro segredo. \\ Tudo é proibido. \\ É preciso, mesmo, \\ estar atento e forte, \\ porque de morte \\ a gente já tá cheio. \\ Na boca, gosto de medo. \\ Difícil mesmo temperar o silêncio. \\ No grito de dor, no prazer temporal \\ do sexo anal. \\ Preenchimento, satisfação. \\ Solitude. \\ O nascimento é o fim do mundo. \\ Ponto final.
}

(Autoria Coletiva, 2017, p. 27)

A leitura do poema acima já impacta pela força de sua construção assertiva. Após apresentar um esvaziamento de título no próprio título, metáfora da indagação de quais corpos são merecedores ou não de designação, de qualificação ou de direitos, segue pondo em questão o segredo do mundo, resguardado pelo interdito, pelo impedimento, numa crítica contundente à colonialidade de poderes e de saberes. Na estrofe seguinte, faz alusão direta à canção “Divino Maravilhoso", composta por Caetano Veloso e Gilberto Gil e interpretada por Gal Costa no Festival da Música Brasileira, da TV Record, em novembro de 1968. Por meio de um jogo paradoxal, para escapar dos censores da Ditadura Militar, a composição dos tropicalistas pedia atenção ao perigo instaurado, mas também às palavras, ao discurso subliminar, à arte e, com isso, trazia a esperança de dias livres e melhores. As imagens da "morte", do "medo", da "dor", do "prazer temporal", do "fim do mundo" designam no poema, ao contrário do furor da juventude dos anos 60, um vazio de expectativas e apontam, unificando o pessoal ao coletivo - haja 
vista a autoria - para a reivindicação ao reconhecimento da existência de sujeitos sociais, excluídos por atravessarem as fronteiras dos gêneros e das sexualidades, impostas culturalmente. Nesse sentido, ao se apoiar numa lógica insurgente e não mais revolucionária, Vida sem título induz mais do que o reavaliar de nossas práticas políticas, e sim, à desconstrução urgente de nossas esteiras teóricas.

Era 2017 a primeira vez em que toquei, abri e li, num jato, os 62 poemas que compõem a Antologia Trans: 30 poetas trans, travestis e nãobinários. Naquele momento, fui tomado por uma sensação extremamente dolorosa, inquietante e prazerosa que, até hoje, não consigo definir. A cada folha virada, a cada poema atravessado, a cada voz ouvida, o peso do objeto em mãos aumentava e aumentava e aumentava. De repente, a pequena publicação de 112 páginas, se tornou tão absurdamente insustentável, que fui obrigado a soltá-la sobre a mesa. Isso porque 30 corpos, historicamente invisibilisados, com vivências, experiências e percepções díspares se debatiam dentro da capa daquele livro. Desde então, a antologia segue em minha cabeceira, na minha bolsa, na minha mala, em mim. Exército a abertura aleatória, releio poemas - uns mais outros menos, evito alguns -, sempre na busca de conseguir um caminho de construção narrativa, a partir dessa plêiade de existências potentes que me foi dada à escuta.

É a primeira vez, em minha carreira de ensaísta, que começo um artigo científico sem saber exatamente o que vou dizer. Não que não saiba o que quero dizer: sei. Aliás, há três anos. Talvez a minha aflição venha do modo como vou dizer. Não, nada disso. Do modo como irei dialogar. É isso! Já que as vozes em destaque serão as de poetas que, com muita dificuldade, selecionei para essa conversa, que eu classificaria como errática para o que se espera de um artigo. E aqui, por isso, já dispenso o termo artigo científico, usado no início desse parágrafo, por entender que a minha fala se dará pela troca, eliminando qualquer tom de autoridade acadêmica, desconstruindo a pretenciosa verticalidade do saber e me refazendo em horizontalidade desejosa de saber, pois como bem revela Linn da quebrada, na orelha do livro: "Aqui onde eram todas uma, em singularidade múltipla, me vejo, reconheço, me encanto, encontro, me perco, me berro, me borro, me melo, me lavo, me leve, me livre, me love, me luta. E então percebo, acabo de não morrer". 
E é seguindo esse viés, levantado por Linn que, após longo tempo de gestação, me permito vivenciar outras formas de estar com os textos da antologia, não só mais me entregando à leitura, mas, sobretudo, me somando pela escrita. Vale ressaltar, que o que me guia, aqui, não é só a tentativa de colocar em palavras a minha inquietação com a obra ou de relatar a minha imensa insatisfação com a figura engessada do intelectual brasileiro que, em sua maioria, detém a palavra e a razão com o seu modo soberbo, retrógrado e monolítico de fazer crítica, sempre calcado em epistemologias imperialistas, gerando uma interpretação e adaptação capengas para a análise da nossa realidade. O que me guia, aqui, é o desejo de procurar, pelo exercício da escuta, amplificar as vozes e contribuir com a visibilidade desses corpos mimetizados que clamam por ser. Adentremos no espaço poético:

Eu não odeio meu corpo.

Eu não nasci no corpo errado.

Não me venha falar que ele é inadequado.

Se eu mudo é para melhorar o que sinto que possa ser melhorado.

Se eu mudo é porque mudança faz parte da vida e eu não quero me sentir parado.

Cada forma.

Cada traço.

São todos pedaços

De quem sou eu.

Comecei só como um rabisco.

Agora estou transcendendo o padrão fabricado.

E ninguém tem nada com isso.

E não tem nada de errado.

Eu sou eterno rascunho da vida.

Nunca vou ser terminado.

Apaga.

Refaz.

Tira.

Acrescenta.

Só não deixa igual, porque aí ninguém aguenta.

Eu não odeio meu corpo.

Eu não nasci no corpo errado.

Sou eterno rascunho da vida, estou aqui para ser melhorado.

Na eterna busca do buscar por toda a eternidade. 
Rabisco

Rascunho

Desenho

Obra prima

Transbordando

Transcendendo

Transgredindo

Apenas sendo mais eu

Mais meu a cada dia.

(Bernardo Enoch Mota, Eu não, 2017, p. 74-5).

O poema intitulado Eu não, revela, no que tange a cuidadosa construção da forma, uma escolha atenta das palavras, um trabalho meticuloso na formação cadencial das rimas, uma refinada estrutura rítmica... enfim, uma riqueza de "valor". Com esse "valor", atribuído a poucos textos literários, qualquer manual canônico de crítica ou de historiografia da área, não duvidaria de alocá-lo na torre conceitual junto ao que se acredita ser uma "boa poesia". No entanto, se a escrita se apresenta dentro dos moldes exigidos para adentrar Oxbridge - numa lembrança da biblioteca ficcional criada por Virginia Woolf, em Um teto todo seu (1929) -, aquele que a produz, nesse caso um homem trans, não está à altura de tal reconhecimento e, com isso, simplesmente, fecham-se as portas, ignorando-se o dito "valor". Atrelado a esse conceito, muitas vezes, estão inúmeras indagações, tais como: o que vem a ser o "valor" e como ele se constrói? Como foi preestabelecido? É imutável ou pode ser transformado? Por que permanece? Perguntas com as quais me deparo, com frequência, não só elaboradas pelos meus alunos e orientandos, nas aulas da graduação e da pós-graduação, mas que se estendem, para fora do espaço da universidade, quando o tema da conversa é a literatura.

Em minha formação como pesquisador feminista e depois queer, as discussões acaloradas sobre as construções e desconstruções de gênero e de sexualidades, as questões de classe e de identidades, as problematizações sobre os conceitos de raça e as formulações pós-identitárias, numa sociedade falocêntrica e colonizadora de corpos e de saberes, me forneceram uma compreensão mais do que simplesmente teórica e conceitual, limitada àquilo que muitos chamavam e ainda chamam, pejorativamente, de "estudos de 
mulheres". A construção teórica, a percepção política e a necessidade da prática, fornecidas pelos estudos feministas, me possibilitaram ampla visão sobre o próprio conceito de teoria que, no meu caso em particular, permitiu um alargamento do olhar no atravessamento pelos caminhos da crítica literária e, por conseguinte, no compromisso do meu fazer pedagógico.

Ler literatura, nesse sentido, se desarticula do espaço de pensar o texto, meramente, a partir das questões de valor, de significado, de tradição, de autoria ou de pontos de vista e da linguagem, bem como de forçados encaixes conceituais. Avançar com esse método é descontruir os alicerces de uma crítica absolutamente normativa - e para mim ultrapassada -, que sustenta as bases ideológicas das desigualdades. Uma leitura queer, que é uma leitura política, de fruição - retomando a imagem avant-garde de Roland Barthes -, possibilita, no dizer da ecocrítica Cherryl Glottfelty, entender que “a literatura não flutua acima do mundo material em algum éter estético, ao invés disso, tem um papel num sistema global imensamente complexo, no qual energia, matéria, e ideias interagem" (GLOTFELTY, 1996, p. XIX). É perceber, a partir desse deslocamento do lugar de onde se olha, a materialidade histórica do discurso e das subjetividades no campo literário; é entender o sentido grandioso de "uma literatura menor" como a articulação da linguagem, do político e do coletivo, como bem explicaram Gilles Deleuze e Félix Guattari:

Uma literatura menor não é a de uma língua menor, mas antes a que uma minoria faz em língua maior. Mas a primeira característica, de toda maneira, é que, nela, a língua é afetada de um forte coeficiente de desterritorialização (DELEUZE; GUATTARI, 2014, p. 35).

$\mathrm{O}$ meu texto se apoiaria, em um primeiro momento (porque ainda me contorço para afrouxar as amarras dos espartilhos da formação que tive), numa perspectiva crítico-literária à teoria que pensei para dialogar com alguns poemas da obra escolhida: a desregulação de gênero e de sexualidades trans, a partir de suas materialidades. Pois, como é sabido, o tema da transexualidade contribui sobremaneira para o estabelecimento de possibilidades de se enxergar as identidades e vivências de sujeitos 
marginalizados, desconstruindo a ideia de um vazio de existência, de uma opacidade, de um “não-corpo", como lembra José Gil, em seu livro Monstros (GIL, 2006, p. 79). Para Sônia Weidner Maluf:

A experiência transgênero é um dos temas que têm possibilitado uma renovação das reflexões, dos conceitos e da própria teoria dentro do campo dos estudos feministas e de gênero. Isso porque - em suas diferentes formas de manifestação - ela tem revelado aspectos do gênero que durante muito tempo ficaram relegados ou à sua construção teórica ou à perspectiva comparativa com culturas outras (MALUF, 2002, p. 148).

Contudo, a partir do clima de insegurança, de desespero e do traçado obscuro que vem se desenhando, nos últimos anos, no Brasil; da emergência de um conservadorismo fundamentalista, dos absurdos e atrocidades com os quais nos deparamos a cada dia, bem como a naturalização e legitimação da violência verbal, simbólica e física, fui inclinado a pensar, para além da análise crítico literária dos poemas da referida Antologia. E, com isso, buscar a importância documental que essa obra guardará, ao ecoar as vozes de pessoas vistas como anormais, doentes e monstruosas por uma sociedade protofascista, declarada e desavergonhadamente misógina, segregadora, racista e LGBTQfóbica.

Nesse sentido, os textos aqui apresentados servirão para entender a Antologia Trans não apenas como um conjunto de poemas que versa sobre uma temática comum, nesse caso, a escrita da transexualidade. Mas, sobretudo, como um arquivo, no conceito elaborado por Jacques Derrida, como um monumento que se escreve fora da ordem vigente. Para o filósofo francês: "Não há arquivo sem lugar de consignação, sem uma técnica de repetição e sem uma certa exterioridade. Não há arquivo sem exterior" (DERRIDA, 2001, p. 22).

Assim, se como afirma Leyla Perrone-Moisés, a "importância da literatura na cultura contemporânea não pode ser defendida fora de uma prática" (MOISÉS, 2016, p. 35), me parece bastante propício, trazer à discussão esse desejo afirmativo de compromisso com o corpo e com o existir, presentes nesse livro. A Antologia se configura como um arquivo, no sentido derridiano, 
ao apresentar 30 poetas trans, travestis e não-binários que, pela potência da palavra poética, se exteriorizam, se multiplicam e se conectam a outras vozes para romper com o "só direito (dever?) de existir à sombra" (p. 11), como bem aponta Amara Moira no prefácio, intitulado “A língua pelos nossos corpos”. Ao preludiar a obra, a escritora ressalta a força desse conjunto literário, no que se refere, principalmente, ao "nosso direito à voz, do nosso direito de pensar palavras que dirão quem somos, quem não somos, nossas versões dos fatos" (p. 11-12). Desse modo, fica evidente a importância não só documental e histórica dessa publicação, mas o seu impacto nesse tempo atual, o que a categoriza como ultra contemporânea, pois, na esteira do pensamento de Giorgio Agamben, lembremos que “[...] o contemporâneo é aquele que mantém o olhar fixo no seu tempo, para nele perceber não as luzes, mas o escuro [...] é, justamente, aquele que sabe ver essa obscuridade, que é capaz de escrever mergulhando a pena nas trevas do presente." (AGAMBEN, 2009, p. $62-63)$.

A constituição de uma obra dessa natureza surge para romper com o paradigma do privilégio heteronormativo "ou, pelo menos para desafiar a sua reivindicação de monopólio da cultura, da história e da autoridade intelectual" (PRATT, 1998, p. 90), como afirmou Mary Louise Pratt. Contudo, ainda que só um desafio, permitindo apenas um "suspiro de meia satisfação", o mundo recomeça e o mal (para os conservadores) está feito, como nos alerta Clarice Lispector, em sua brutalidade sutil, no desequilíbrio do conto Amor. Aqui, não é um cego parado, mascando goma que despedaça uma existência, mas "corpos em aliança" que saem da zona obscura a que foram sempre relegados, se escrevem e se reescrevem, despedaçando a hipocrisia social, moral e religiosa. E se o trem já partira, ainda clariceando, não há como voltar. Taxativamente Amara Moira diz:

As palavras não-nossas em que temos podido existir, desconfortáveis, inconsistentes, vamos finalmente criando condições para dizer que elas não nos refletem, não nos contemplam. [...] Os olhos que nos veem, pelos quais por tanto tempo nos vimos, não mais nos servem. $\mathrm{O}$ mundo, hoje, o sentimos nosso, também nosso, e já não nos contenta somente armário ou beco nem a sujeição 
aos padrões cis que nos têm sido impostos (MOIRA, 2017, p. 12).

E é, assim, pela própria língua de seus próprios corpos, que se apresentam como sujeitos, não mais estereotipados e marginalizados, mas orgulhosos, se inscrevendo pela autorrepresentação. Num jogo de ressignificação do discurso hegemônico, pela escrita de si e, consequentemente, do outro, porque estamos falando de literatura, se estabelece a desterritorialização da língua maior:

As fotos me contam histórias sobre o passado.

A cegueira me impede de ver o presente.

O tempo dilacera, machuca, apodrece.

Quem deve dizer o que se merece?

Os olhares me assanham, às vezes zombam.

No meio do caos encontro a pintura.

As cores dançam e a pele treme.

O mundo para em um momento de ternura.

O que resta dizer de mim?

Que se perde, confunde, machuca?

Que palavras conseguem cantar o que sai do coração?

Desse vazio surge apenas uma exclamação:

Meu Deus! Eu sou humana!

(Calla, Uma exclamação, 2017, p. 32)

Constituído numa oficina literária, num curso popular, dirigido pelo Coletivo TransFormação, os poemas levantam discussões, pelas práticas do cotidiano, sobre as subversões identitárias e as problemáticas de gênero, já iniciadas há algum tempo, teoricamente, por Judith Butler, e tão refletidas entre os pesquisadores do tema. E em acordo com esse pensamento, a leitura do livro, numa crítica à heteronormatividade compulsória, nos leva a refletir sobre a percepção equivocada do senso comum, que entende que "a regulação implícita de gênero acontece por meio da relação explícita da sexualidade" (BUTLER, 2017, p. 710) e que a naturalização do binarismo humano X inumano - representado nas categorias homem $\mathrm{X}$ mulher, masculino $\mathrm{X}$ feminino, 
heterossexual X homossexual - , sedimenta a interpelação fundante pelo caráter performativo da linguagem:

Quem disse que ser trans me torna passiva? Que roteiro diz que a feminilidade me torna submissa? Hierarquia sexo social, que capitaliza até meu jeito de foder.

Indústria do pornô que diz que meu sexo é pra vender.

A única forma permitida de desviar é se for pra gerar lucro,

e me comercializar?

Essa indústria também é responsável por endeusarem o macho e iconizar.

Aaaaaah, se manca.

Seu sistema é frágil e não vai me dominar. Nem pense em impor desejo para o seu comércio. As bixa não vai deixar passar.

A sua ideia de ser homem não é suficiente para todos os corpos com os quais eu vou transar. E como vou transar?

Pega seu sexo baunilha, de papai e mamãe e afasta pra lá A minha foda não é para reprodução.

É para emancipação.

Adeus colonização.

Conhecer os corpos, experimentar, compartilhar.

E viado, nem venha demonizar nossa vagina. Ele pode ser homem de xoxota e consegue, sim, me realizar.

Afasta de mim esse falo.

Não me diga o que é ser macho. Invisibilizar trans homem, só revela o quanto seu desejo é manipulado.

Para o corpo como objeto de simulacro, desejo de consumo do patriarcado. Na base do teu sexo social, o corpo do viado feminino, 
se torna invisível e solitário.

O macho branco forte rico e musculoso tá no topo.

E quando ela é bixa, trans, preta, gorda e pobre:

“joga pra margem, pro esgoto".

Estamos na base dessa cadeia,

Mas não é por isso que eu abaixo a cabeça.

E nem me peça para foder.

Sou desejada,

mas só quando ninguém vê.

Hahaha

sei que não somos opção,

só nos escolhe quando somos resto.

Pensa que vou foder só pra te satisfazer?

O meu prazer não importa quando

a sua pica goza

no escuro do banheiro e já quer me esconder,

só pra defender que bixa é depósito de porra,

que não é de merecer andar ao teu lado,

nem de reconhecer.

Somos transbixa e temos poder.

E você gay, não é obrigado a "enviasdescer".

Até porque ninguém quer perder

O PRIVILÉGIO

De parecer

E nem quer ser atacado por outros machos

que não aceitam um corpo de pau feminino.

Agora me diga, macho:

- Quando você foi proibido de ser homem?

- Quando te condenaram por ser homem cis?

- Quantas vezes te forçaram a ser homem?

- Quantas vezes você ouviu que não pode?

É.

Bem diferente de ser transviado.

(Lucy Lazuli, Descoloniza, 2017, p. 93-5).

Descoloniza, a partir das indagações da primeira estrofe, traz à discussão uma verdade cristalizada culturalmente sobre a construção da 
tríade sexo-gênero-sexualidade como um esquema fechado e sequencial e, através, de outras verdades, exibe as marcas profundas nos corpos colonizados pela lógica heteropatriarcal. Contudo, se não há como apagar as cicatrizes, é possível tatuar sobre elas outras imagens, que permitam outros modos de ser e de agir, decolonialmente. Já em 1990, ao publicar o tão conhecido Problemas de gênero: feminismo e subversão da identidade, Butler desenvolve inúmeras inquirições sobre o sintagma que abre o título de seu livro (Problemas). Trazendo a biologia para o campo social, indaga se o sexo seria realmente uma estrutura fechada, inquestionável e indiscutível, pela sua força de materialidade. Para dar embasamento às suas argumentações, questiona a veracidade e o valor da ideia cristalizada de que o sexo está diretamente ligado ao corpo e à natureza, destituído do campo social, lugar no qual se discutia sobre o gênero. Assim, acompanhando o pensamento da filósofa estadunidense, o gênero não é nem um conjunto de significados culturais inscritos num corpo nem a interpretação cultural de um corpo sexuado e também ser homem ou ser mulher não constituem uma essência interior da "pessoa", mas um conjunto de normas instituídas, mantidas e repetidas sobre o corpo que geram essa aparência de substância e torna a pessoa culturalmente viável (humana) ou inviável (inumana):

Não, eu não sou um homem de verdade.

Definitivamente não sou, nunca serei.

Vou te falar o que sei sobre homem de verdade.

É forma viva da sapiência e erudição que mija fora do vaso,

senta de perna muito aberta no busão,

te agride se sente que está perdendo o altar em que se fez macho,

escarra forte no chão.

Tá sempre calculando o nível do esculacho que vai direcionar sem dó

para todo e qualquer ser vivo desviante da condição de submissão

cis-heteronormativa.

E eu juro que não tô gastando palavra bonita, que comigo o verbo é torto mesmo, como eu sempre fui. 
Não, homem de verdade eu não sou, não.

Eu saí de uma outra fornada.

Eu nasci e fui criado

na feminilidade,

me ensinaram que a minha genitália foi criada

para se invadir.

Fecha a perna, garota.

Não usa esse short perto de menino,

é curto demais.

Não adiantou.

Eu to vivendo a consequência da minha invasão desde 1999.

Hoje eu tenho 23 anos

Cês tão fazendo a conta?

Porque homem que é homem de verdade, não faz.

Nem da idade, nem do consentimento.

Palavra que vários deles não conhecem,

tipo clitóris, orgasmo, fazer gozar

e pode parar,

para agora mesmo.

Nesse poema não tem espaço pra problematização nem pra feminista radical sorrir de escárnio pensando em socialização.

Eu to falando de masculinidade.

Vamo combinar que é um problema maior que a vulnerabilidade da buceta.

Até porque eu conheço homens de buceta que a cada dia que passa

estão se esforçando pra ser homens de verdade jogando no vento a carta da criação, justificando incansavelmente a reprodução daquilo que os fez sofrer tanto quanto eu.

Pronto, falei.

Saiu direto das minhas tetas indesejadas, da minha ausência de pelo e falo, da minha voz aguda,

da baixa estatura, da inconfundível distribuição muscular,

dos meus quadris largos, 
da minha raxa.

Tá bem aqui o boy que vai humilhar a masculinidade de vocês.

E cês pode crer que a minha arma

tá pronta e empunhada

por mim e pelas minhas irmãs.

Quem tá apontando é cada mina cis, trans e travesti, cada transviado, cada bicha,

cada uma das pessoas afeminadas que vocês querem destruir.

(Teodoro Albuquerque, Construção, 2017, p. 109-111).

Num tom de manifesto "para todo e qualquer ser vivo desviante da condição de submissão / cis-heteronormativa", Construção aponta para aspectos estruturantes da matriz de dominação de corpos e sugere, assim como Butler, que as identidades múltiplas de seres que vivem "na ambiguidade", ou vivem "a ambiguidade" brincam com a lei de que de um sexo decorre um gênero, e mais do que isso, significam claramente que ser de um gênero parece inevitavelmente "teatralizar" a ideia original desse gênero; as "falas", a representação que esse gênero estabelece. Como nos lembrar Butler:

As estruturas jurídicas da linguagem e da política constituem o campo contemporâneo do poder; consequentemente, não há oposição fora desse campo, mas somente uma genealogia crítica de suas próprias práticas de legitimação. Assim, o ponto de partida crítico é o presente histórico, como definiu Marx. E a tarefa é justamente formular, no interior dessa estrutura constituída, uma crítica às categorias de identidade que as estruturas jurídicas contemporâneas engendram, naturalizam e imobilizam (BUTLER, 2003, p. 22).

A partir das suas críticas e das suas propostas de subversão da ordem compulsória, amparado em profunda discussão sobre registros cristalizados, é que Problemas de gênero: feminismo e subversão da identidade, numa renovação do olhar sobre os sujeitos de gênero e de sexualidades, pode ser considerado como a virada pós-estruturalista da teoria feminista e uma base importante de reflexão para as questões queer. E, em concomitância, os poemas aqui apresentados, "mostrando o mundo que existe 
para os corpos trans, sem [...] abrir mão da experimentação com a linguagem e do compromisso com a palavra em sua inteireza" (MOIRA, 2017, p. 13), se estabelecem como potências que nos permitem entender, na prática, a desregulação do gênero, pois, ao evidenciar a artificialidade dos discursos e das técnicas empregados nas normatividades, examinam a produção de sujeitos pelas instituições políticas representativas:

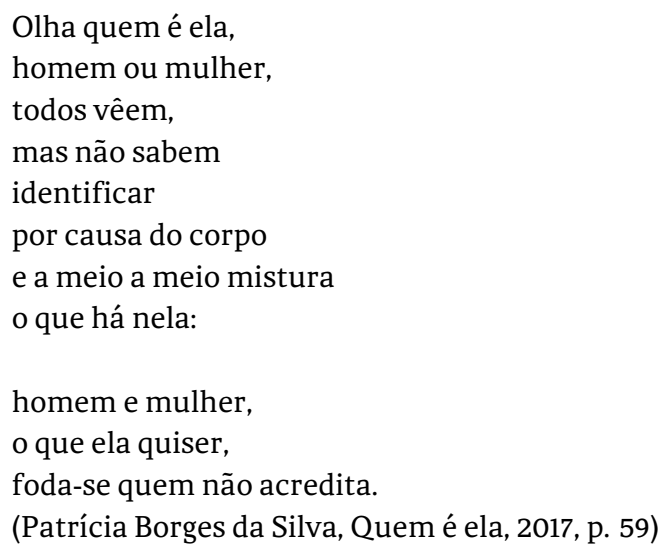

Desse modo, se lembrarmos de Antonio Candido, ao afirmar que a "produção literária tira as palavras do nada e as dispõe como todo articulado" (CANDIDO, 2004, p. 177), perceberemos a importância da Antologia Trans, para adiante da revelação que "vidas transgênero são evidências do desmonte de quaisquer linha de determinismo causal entre sexualidade e gênero" (BUTLER, 2017, p. 712), mas, principalmente como ampliação, renovação e ressignificação dos olhares sobre os corpos entendidos como abjetos, aos quais sempre foram negados o estatuto de humanidade. Ainda com Amara Moira:

O mundo não foi pensado para nós, suas burocracias, regras, seu apego às máscaras, gavetas trancafiadas, armários; talvez por isso o medo ante essas figuras, nós, que ousamos nos descobrir para além das máscaras que nos pregaram no rosto. Você é o que você é ou o que te criaram para ser? Quanto mais conseguimos falar, ocupar, resistir, mais vai se fazendo difícil defender que gênero é mera decorrência do genital, mais vai se fazendo risível nossa existência tão óbvia, tão necessária. As 
verdades que trazemos aqui, escancaradas em prosa e verso. Ai de quem se permitir conhecê-las... (MOIRA, 2017, p. 13).

\section{Referências}

AGAMBEM, Giorgio. O que é o contemporâneo? e outros ensaios. Trad. Vinícius Nicastro Honesko. Chaapecó, SC: Argos, 2009.

ANTOLOGIA TRANS: 30 poetas trans, travestis e não-binários. Ed. textos Carmen Garcia; Élida Lima; João Pedro Innecco. 1a reimpressão. São Paulo: Invisíveis Produções Editora, 2017.

BUTLER, Judith. Problemas de gênero: feminismo e subversão da identidade. Trad. Renato Aguiar. Rio de Janeiro: Civilização Brasileira, 2003.

BUTLER, Judith. "Regulações de gênero." In: BRANDÃO, Izabel; CAVALCANTI, Ildney; LIMA COSTA, Cláudia de; ACIOLI LIMA, Ana Cecília (Org.). Traduções da cultura: perspectivas críticas feministas (1970-2010). Florianópolis: EDUFAL; Editora da UFSC. p. 692-716, 2017.

CANDIDO, Antonio. Vários escritos. 4 ed. Rio de Janeiro: Ouro sobre Azul; São Paulo: Duas Cidades, 2004.

DELEUZE, Gilles \& GUATTARI, Félix. Kafka: por uma literatura menor. Trad. Cíntia Vieira da Silva. Belo Horizonte: Autêntica Editora, 2014.

DERRIDA, Jacques. Mal de arquivo: uma impressão freudiana. Trad. Cláudia de Moraes Rego. Rio de Janeiro: Relume Dumará, 2001.

GIL, José. Monstros. Lisboa: Relógio D’Água Editores, 2006.

GLOTFELTY, Cheryll and FROMM, Harold; eds. The Ecocriticism reader landmarks in literary ecology. Athens and London, Univ. of Georgia Press, 1996.

MALUF, Sônia Weidner. Corporalidade e desejo: Tudo sobre minha mãe e o gênero na margem. In: Estudos Feministas. Florianópolis. Universidade Federal de Santa Catarina, 10 semestre 2002. Ano 10, p. 143-152. Disponível em: http://www.scielo.br/pdf/ref/v10n1/11633>. Acesso: 20 de setembro de 2015.

PERRONE-MOISÉS, Leyla. Mutações da literatura no século XXI. São Paulo: Cia das Letras, 2016.

PRATT, Mary Louise. “'Don't interrupt me': The gender essay as conversation and countercannon". Revista Brasileira de Literatura Comparada, no 4, 1998, p. 90. 
PEDAGOGIAS DE SER: ESCUTA E VISIBILIDADE DE CORPOS EM ANTOLOGIAS TRANS

WOOLF, Virginia. Um teto todo seu. Trad. Vera Ribeiro. 2. ed. Rio de Janeiro: Nova Fronteira, 2004.

Recebido em 13 de outubro de 2020.

Aceito em 30 de outubro de 2020. 